\title{
Desenvolvimento do self e processos de hiperindividualização: interrogações à Psicologia Dialógica
}

\author{
Maria Cláudia S. Lopes de Oliveira* \\ Universidade de Brasília, Instituto de Psicologia. Brasília, DF, Brasil
}

Resumo: Em psicologia, à perspectiva dialógica estão associadas teorias do self, em especial a Teoria do Self Dialógico (TSD). Embora avanços consistentes venham sendo alcançados no que se refere à compreensão da organização dinâmica da estrutura do self no tempo microgenético, a teoria carece de estudos que se aprofundem na compreensão do desenvolvimento do self, tomando-se por base os distintos níveis temporais e suas relações. Este estudo propõe explorar essa lacuna, tomando por ponto de partida a tríade epistemológica da abordagem dialógica, a saber, suas bases semiótico-culturais, fenomenológicas e construcionistas. Em seguida, apresentará um estudo de caso em que serão analisadas as transições de desenvolvimento de um adolescente, considerando-se os complexos semióticos de gênero, raça e religião e seu papel nas transformações vividas em termos da organização temporal do self.

Palavras-chave: desenvolvimento humano, enfoque dialógico, processos de estabilização, teoria dos campos afetivos, hiperindividualização.

\section{Introdução}

Ao se considerar as bases semiótico-culturais, fenomenológicas e construcionistas que participam do arranjo epistemológico que fundamenta a psicologia dialógica, um aspecto importante que a pesquisa na área deve considerar diz respeito ao conceito, ao papel e às relações estabelecidas entre estrutura, experiência e tempo. Tal questão é central para o campo de investigação dos processos de desenvolvimento humano e, em particular, quando o interesse investigativo volta-se à construção temporal do senso de unidade psicológica da pessoa, ou self, em meio à multiplicidade de experiências singulares vividas, interesse deste artigo.

No que se refere à investigação do desenvolvimento humano, há estudos recentes que se dedicaram a aprofundar a compreensão do fenômeno da mudança psicológica à luz da perspectiva dialógica (cf. Hermans \& A. HermansKonopka, 2010, Moore, Jasper \& Gillespie, 2011; Zittoun, 2014), mas esses acompanham a tendência de olhar de forma mais enfática para os processos de transição, as passagens e rupturas do que para possíveis momentos de estabilização, que a dinâmica desenvolvimental possa promover. A nosso ver, o foco investigativo sobre mudanças é de fundamental importância para o tema do desenvolvimento humano, mas a ênfase demasiada sobre a dinamicidade da organização do self leva a modelos interpretativos nos quais deixa-se pouco espaço para a estabilidade psicológica, ou, em que os processos de estabilização tendem a se confundir com interrupção do desenvolvimento.

\footnotetext{
* Bolsista de produtividade em pesquisa do CNPq. (310848/2013-0)
}

Endereço para correspondência: mcsloliveira@gmail.com
A reflexão sobre movimentos de estabilização remete a outras indagações, que se referem à existência e à natureza de algo que se poderia denominar o núcleo mínimo do sistema de self, algo que constitua ou se converta em pessoal e singular, permanecendo relativamente íntegro no tempo, em meio à pluralidade de experiências pessoais e aos processos intransitivos de desenvolvimento. Assim sendo, o objetivo deste artigo é aprofundar o debate sobre o desenvolvimento do sistema de self, desde uma perspectiva que integra a psicologia semiótico-cultural e a psicologia dialógica. Parte-se dos resultados de um estudo empírico, de corte idiográfico, em que se abordam os fluxos de desenvolvimento ontogenético e de organização do sistema de self de adolescentes diante da performance de gênero não normativa. Analisamos um estudo de caso no qual encontramos situações exemplares que ajudam a avançar na compreensão semiótica dos processos de estabilização a partir do conceito de hiperindividualização.

$\mathrm{O}$ artigo está dividido em três partes: a primeira apresenta uma breve revisão das matrizes epistemológicas e teóricas que comparecem na construção do paradigma dialógico e de alguns de seus desdobramentos, na atualidade; a segunda apresenta e discute o estudo de caso; e a parte final ensaia algumas contribuições e avanços teóricos com base no estudo de caso.

\section{Psicologia dialógica: a construção de uma epistemologia do self em desenvolvimento}

A psicologia dialógica é considerada uma das mais promissoras linhas de desenvolvimento da psicologia contemporânea. Seu programa investigativo, que se estende por diferentes temáticas de pesquisa e áreas de inserção prática da ciência psicológica encontra-se disseminado mundo afora, conforme se pode atestar pelos participantes 
que atendem aos encontros científicos da área (Gomes, 2006). Em meio à profunda diversidade de interesses e desdobramentos teóricos, algumas temáticas se sobressaem nos estudos, que foram sistematizadas por diferentes autores (Bento, Cunha \& Salgado, 2012; Branco \& Lopes de Oliveira, 2014; Salgado \& Cunha, 2012; Salgado \& Gonçalves, 2007):

Self. A psicologia dialógica postula ser uma epistemologia apropriada ao estudo do self, ao tomar por objeto o ser humano na sua complexidade e totalidade, em processo de crescente integração, e não processos ou funções psicológicos específicos e potencialmente divorciados entre si e da corporeidade.

Signo. A abordagem dialógica mantém coerência com uma compreensão semiótica dos fenômenos humanos, ao enfatizar o papel dos signos, as peculiaridades dos processos de significação na constituição, na conduta e na transformação da pessoa na linha do tempo. Tal como enfatiza Taylor (1997), como agentes, somos orientados por aquilo que é significativo para nós.

Outro. Orienta-se, naturalmente, pelo dialogismo, destacando o papel do álter e dos processos relacionais (interação, comunicação etc.) na configuração do psiquismo.

Tempo. O enfoque dialógico caracteriza-se como uma abordagem sociogenética, ao focar as mudanças da pessoa, na linha do tempo, mediadas por sistemas particulares de atividade socioinstitucional. Considera-se que a pessoa forma uma unidade dialética com o contexto social, mediada pelos cenários institucionais concretos.

Experiência. O foco da psicologia dialógica são os sujeitos em ação, nas relações eu-mundo, na vida cotidiana, nas trocas e interações em que se produzem e negociam os significados. A noção de experiência foi por muito tempo relegada ao segundo plano em modelos psicológicos baseados na fragmentação do humano, mas mostra-se de fundamental importância em uma psicologia centrada na totalidade pessoa-outro-realidade (Gaspar \& Mahfoud, 2006).

Esse brevíssimo recorte do conjunto de características que pensamos definir o programa de pesquisa da psicologia dialógica já se mostra capaz de destacar o importante valor heurístico representado pela abordagem para a compreensão dos processos de desenvolvimento humano, no contexto epistemológico da contemporaneidade. As vicissitudes de nosso tempo têm demandado das ciências sociais a elaboração de perspectivas capazes de, não apenas integrar subjetividade e alteridade, mas de pensar tal relação a partir da diferencialidade sujeito-outro, em sua acepção mais profunda.

A compreensão da pessoa no paradigma dialógico implica recolocação da questão do indivíduo, conceito que foi tão marcante na psicologia moderna. É coerente afirmar que a modernidade foi marcada por uma visão egológica (Salgado e Cunha, 2012). Coube a Descartes fundar o projeto filosófico que mais contribuiu para a supervalorização do indivíduo, uma característica que perpassou o projeto político da modernidade. Essa mesma orientação ajudou a construir e contribuiu para desenvolver os aparatos sociais necessários à internalização da autoimagem do sujeito liberal. $\mathrm{O}$ autor colaborou, da mesma forma, para fundar as bases filosóficas do processo em que a unicidade do indivíduo se converteu em categoria de inteligibilidade da condição humana, o que foi fundamental para a consolidação das transformações econômicas e sociopolíticas que se seguiram, em especial, à Revolução Industrial.

No projeto científico da modernidade, tocou à Psicologia nascente, no final do século XIX, a tarefa de compreender o indivíduo, na sua interioridade (Sampson, 1993/2008). No movimento de consolidação da ciência psicológica, o indivíduo foi progressivamente assumindo a forma de uma entidade independente, autônoma, autocontida, isolada, passível de ser dividida em partes objetivamente apreensíveis pelo aparato metodológico científico (Hermans, 1992; Lopes de Oliveira, 2003).

Deve-se salientar, no entanto, que tal visão solipsista do sujeito não foi exclusiva na história da psicologia. Diferentes matrizes filosóficas e psicológicas, que corriam em paralelo, ressaltaram ou deixaram espaço para que se pensasse o sujeito social, em gênese constante e necessariamente integrado à realidade sociocultural, a exemplo dos próprios pioneiros $\mathrm{W}$. Wundt (Alemanha) e W. James (EUA).

Ainda que sejam mais reconhecidos por sua contribuição à psicologia experimental, ambos deixaram legados à psicologia cultural, em geral, pouco destacados pelos historiadores da psicologia. De Wundt, há a obra densamente elaborada (10 volumes), denominada Volkerpsychologie (psicologia dos povos), em que trata de temas como a evolução psíquica dos povos, a vida humana em coletividade e outros, em que ressalta a unidade dialética sujeito-contexto (Ericeira, 2007). No que se refere a W. James, sua clássica obra Principles of psychology (James, 1890) traz um debate singular sobre a categoria de self, que será amplamente explorada por diferentes autores da abordagem dialógica. Nela, o self é definido como um self estendido, relacional, que inclui necessariamente a alteridade:

O self de um homem é a soma de tudo o que ele $\mathrm{PODE}^{1}$ chamar de seu, não apenas o seu corpo e capacidades psíquicas, mas suas roupas e sua casa, sua esposa e filhos, seus ancestrais e amigos, sua reputação, seu trabalho, suas terras, iate, conta bancária. Tudo isso lhe proporciona as mesmas emoções. Se elas prosperam, ele se sente triunfante; se elas declinam ele se sente impotente, não exatamente o mesmo tanto, mas quase sempre da mesma forma em todos os $\operatorname{casos}^{2}$ (p. 291-292)

Observe-se que, a despeito de exibir uma descrição coerente com seu contexto histórico-cultural, traduzida

1 Ênfase dada por meio do uso de maiúsculas no original.

2 Tradução livre da autora. 
na imagem liberal capitalista do homem (proprietário de terras, iate e conta bancária), James ousa ao apostar numa concepção de self espacialmente expandido, que inclui elementos sociais e do entorno, diferente da imagem solipsista predominante na ciência da época. Guardando uma proximidade com esse modelo compreensivo, a psicologia dialógica caracteriza o ser humano como homo multiplex, ou seja, um agregado de relações sociais internalizadas (Bakhtin, 1989; Pino, 2005; Vygotsky, 2000), cuja natureza se define pela relação com o outro, sempre mediada pela experiência intersubjetiva, no cerne da qual se produzem significados. $\mathrm{O}$ desenvolvimento psicológico mantém forte interdependência com a alteridade (não eu) e com a realidade sociocultural na qual se constitui.

Sendo o psiquismo uma estrutura semioticamente mediada, os signos têm um papel central na configuração psicológica, a qual se expressa socialmente e se organiza dialogicamente por meio de histórias. Dito de outro modo, o ser humano é um narrador que vive sua condição humana por meio das narrativas que apresenta, nas quais costura sua história pessoal e encadeia sua existência a das outras pessoas.

Na próxima seção, o objetivo é abordar alguns dos principais fundamentos filosóficos e teórico-epistemológicos que influenciaram aqueles que construíram as bases da psicologia dialógica, sem a pretensão de esgotá-los. São eles: a fenomenologia, o construcionismo e a psicologia semiótico-cultural.

\section{A fenomenologia dialógica}

A centralidade das noções de experiência, existência e intencionalidade, como características do ser humano, aproximam o dialogismo da fenomenologia. No que se refere às bases fenomenológicas do dialogismo, podemos evocar distintas matrizes que desembocam do pensamento de E. Husserl e que marcam, de modo diverso, os desdobramentos contemporâneos da psicologia dialógica: de um lado, há nomes como M. Heidegger, Merleau Ponty, M. Buber e E. Levinas; de outro lado, Mikhail Bakhtin trata de uma fenomenologia dialógica que é apresentada em seus estudos bem iniciais, quando era um jovem professor de filosofia e travava um embate com as perspectivas neokantianas, a cujo imperativo ético ele opunha a ênfase na experiência situada (Holquist, 1993; Lopes de Oliveira, 2013).

A fenomenologia de Heidegger representa uma linha filosófica da primeira metade do século XX, que busca romper com a ontologia metafísica herdada da filosofia cartesiana, ao apostar nas ideias de unicidade, consciência, intencionalidade e finitude do ser como elementos para uma nova ontologia (Zuber, 2011). Por oposição à dualidade mente-matéria de Descartes, o ser da fenomenologia se manifesta no ser-aí, é interdependente da existência concreta, o que conduz a uma perspectiva na qual o sujeito é concebido como ser-aí (dasein). Em poucas palavras, a "essência do ser" que, para a metafísica seria universal e atemporal, para a fenomenologia está relacionada à existência, manifestando-se e podendo ser compreendida a partir das formas concretas da vida cotidiana, as relações da pessoa no mundo.

Quanto tratamos de Merleau-Ponty, o foco de sua investigação recai sobre a experiência do mundo como produto de um ato perceptivo por uma consciência intencional e encarnada, cuja relação com a realidade é dialética (Chauí, 2002). Merleau-Ponty confere um papel destacado à corporeidade, considerando o corpo o lugar onde a subjetividade pode ser revestida de uma situação ao mesmo tempo física e histórica (Gonçalves, Garcia, Dantas \& Ewald, 2008). Desse modo, a experiência é vista pelo filósofo como ato ao mesmo tempo pessoal e cultural, unidade dialética subjetividade-objetividade.

As ideias de Buber - como as de Levinas - têm traços de continuidade e de ruptura com as anteriores. No que se refere a Buber (2001), sua visão de homem é da mesma forma influenciada por Feuerbach (citado por Buber, 2001), de quem ele herda os princípios da filosofia do diálogo:

O homem, individualmente, não possui a natureza humana em si mesmo nem como ser moral nem como ser pensante. A natureza do homem é contida somente na comunidade, na unidade que repousa exclusivamente sobre a realidade da diferença entre o eu e o tu. (parágrafo 59)

Assim, o primeiro plano de sua atenção não é a unicidade do ser (versus o dualismo cartesiano), mas seu caráter relacional, o fato de que o ser se constitui na relação sujeito-outro. Nesse sentido, a intersubjetividade é tomada como o contexto primário de emergência do ser, e que prepara o terreno para a subjetividade. Seguindo Feuerbach, Buber considera que há completa primazia da relação com o outro sobre a relação de cada um consigo mesmo e com a própria realidade. Nuto (n.d.) destaca as influências mútuas e aproximações que se podem identificar entre o dialogismo de Buber e o de Bakhtin. Entretanto, deve-se considerar que o primeiro representa um dialogismo considerado ingênuo, ao fundamentar-se em uma compreensão idealizada das pessoas em interação. Para Buber, as relações sociais seriam caracterizadas por posições simétricas entre o Eu e o Tu, condição que possibilitaria a plena circulação do discurso, sem barreiras comunicativas ou incompreensões. Ele desconsidera a ocorrência de tensão e conflito como eventos mediadores das relações sujeito-outro e de cada um consigo mesmo. Tal visão conflitual das relações humanas está presente em Bakhtin e será acolhida com vigor pela psicologia dialógica.

E. Levinas segue a trilha da ontologia relacional preparada por Buber, mas a amplia, convertendo-a em uma ética relacional, cujos fundamentos se assentam, em última instância, na filosofia da religião. Para Levinas (2004), aquilo que caracteriza o humano na sua essência é um posicionamento moral responsável, traduzido na "consciência ética de servir ao outro" (Meneses \& Reis, 2009, p. 112), sendo o aspecto primeiro da subjetividade 
sua sensibilidade à alteridade. Tal posição empática é constituída na relação face a face com o outro, acolhido e respeitado na sua diferencialidade constitutiva. $\mathrm{O}$ outro representa sempre um mistério para o eu (Hermans \& Hermans-Konopka, 2010; Simão, 2012) e a diferença irreconciliável sujeito-outro, a que Levinas (2004) denomina "alteridade radical", é ao mesmo tempo uma fonte potencial de assimetria e conflito interpessoal. Entretanto, esses aspectos são considerados essenciais para se chegar a compreender as relações humanas.

Em relação a Bakhtin, as bases para a construção de uma fenomenologia dialógica (Lopes de Oliveira, 2013) encontram-se delineadas em seus textos mais precoces, especialmente "Por uma filosofia do ato" (Bakhtin, 1994) e "Autor e herói na atividade estética" (Bakhtin, 1997). Nesses trabalhos, ele caracteriza o elo entre uma visão de sujeito ancorado na realidade social, que se constitui como tal em meio às relações sociais mediadas pelas formas e gêneros de comunicação. A atividade dialógica, a qual Bakhtin situa no fluxo dos atos intencionais, é realizada contra o background dos contextos culturais e ideológicos. Um conceito central presente nesses dois trabalhos, que transversaliza o dialogismo bakhtiniano, é o de ato responsável que, conforme Nuto (n.d.), aproxima-se do conceito de responsabilidade, encontrado em Buber. $\mathrm{O}$ ato responsável é aquele no qual a ação do Eu, e suas consequências sobre o outro, são tomadas como uma totalidade. A relação entre causa e efeito, que se estabelece no ato responsável, não é de natureza lógica, como se caracterizava na metafísica kantiana, por exemplo, mas semiótica. A responsabilidade é definida a partir de transações simbólicas que ocorrem contra o pano de fundo de uma realidade sociocultural.

A realidade não é concebida por Bakhtin como organizada e coerente, mas sim caótica, e por isso ela nunca pode ser compreendida de dentro. Para chegar a compreender a realidade, exige-se do sujeito que ele tome certa distância do vivido, assumindo o lugar do outro, por meio do excedente de visão/exotopia (Lopes de Oliveira, 2013). O ato responsável é "responsivo", ou seja, caracteriza-se pela ativa sensibilidade ao outro e pelo compromisso com ele.

\section{Construcionismo e dialogismo:}

Rasera e Japur (2005) definem o construcionismo social como um movimento de crítica ao desenvolvimento da ciência, que serviu de base para o desenvolvimento de concepções alternativas ao pressuposto do conhecimento individual. Tal crítica se pauta em três dimensões: crítica social, ideológica e retórico-literária. Considera-se que o construcionismo chegou à psicologia em 1973, com o texto "Social Psychology as history", de Kenneth Gergen. De lá para cá, múltiplas foram as linhas de desenvolvimento que o movimento assumiu na psicologia, de forma que, segundo os mesmos autores (Rasera e Japur (2005):

estas três críticas redimensionam as teorias científicas, explicitando seu caráter comprometido, sua determinação histórico-cultural e enfraquecendo uma visão da ciência como uma descrição objetiva e acurada da realidade, na qual a linguagem é sustentadora da verdade. (p. 22)

As linhas de desenvolvimento do construcionismo e das abordagens dialógicas se cruzam, de modo especialmente relevante, pela mediação dos autores do self dialógico. Essa perspectiva teórico-metodológica emerge, em um primeiro momento, como catalizadora de pesquisas e reflexões no campo da psicoterapia, em que se destacam as orientações construcionistas e narrativistas. Autores como Hermans (1992, 2001), Hermans e Hermans-Konopka(2010) e Cresswell (2011) são porta-vozes de um diálogo ativo entre a psicologia dialógica e a psicologia construcionista social, em especial, a versão que se desenvolve em torno do trabalho de Gergen (1991), o que não se estabelece sem restrições. A metáfora que Gergen cria para falar de um self "saturado" de relações sociais mostra-se coerente com a crítica dialógica ao indivíduo autocontido e descontextualizado entalhado pela modernidade. Entretanto, percebe-se que, à luz do construcionismo social, o sujeito torna-se frágil, reduzido a um mero atravessamento de elementos díspares, na forma de múltiplos discursos e representações sociais não coesas (a que Gergen denomina "multifrenia"). Ao sujeito do construcionismo não se atribui unidade interna, ele se desmembra em distintos papéis sociais, evocados conforme a situação. De acordo com essa visão, deixa de haver espaço para uma mínima estrutura, agência ou intencionalidade da pessoa na ação dirigida ao outro. De acordo com Hermans \& Hermans-Konopka (2010),

Aparentemente, de acordo com certos enfoques do construcionismo social, a contingência e a não homogeneidade dos posicionamentos discursivos são tomados como razão para se rejeitar o self como categoria teórica. De modo diverso, argumentamos, seguindo Falmaigne, em favor de um self corporeificado e forte, ainda que incorpore a multiplicidade, a heterogeneidade, a contradição e a tensão. Nós não vemos essas características como vindo a constituir um impasse para se teorizar sobre o self, mas como aspectos "intrínsecos"3 ao self corporeificado (embodied). (p. 49)

A despeito das críticas implícitas ao sujeito do construcionismo social, deve-se reconhecer que essa vertente deixa marcas importantes na psicologia dialógica, em especial, no que se refere ao método, expressas na prevalência de estudos que tomam as narrativas e a produção de histórias como instrumentos para o acesso e a compreensão do self dialógico.

3 Aspas no original, utilizadas certamente no intuito de relativizar o "peso" semântico da expressão, dada a crítica do autor à ideia de uma interioridade do self, separada da externalidade social. Tradução da autora. 


\section{A perspectiva semiótico-cultural: desdobramentos do dialogismo}

O conceito de cultura tem sido amplamente explorado nas ciências humanas e sociais. O estudo de revisão de literatura desenvolvido por Kroeber \& Kluckhohn (1952) identificou cerca de 160 diferentes definições e caracterizações desse fenômeno. Jahoda (2012) implementa nova revisão de literatura, tomando por base os estudos transculturais e identifica três grandes grupos de teorias: as que situam a cultura externamente à pessoa; as que a investigam no interior das pessoas; e as que posicionam a cultura como fenômeno de fronteira. Esse sistema de categorização dos estudos é frutífero, mas está longe de esgotar a amplitude do fenômeno. De acordo com Valsiner (2012), o acúmulo histórico levou à multiplicação de descrições do processo pelo qual um sujeito passa a sentir-se parte da coletividade pela incorporação do sistema de valores e hábitos da comunidade, mas o campo dos estudos culturais carece de uma verdadeira teoria da cultura, que contribua para explicar por que o ser humano desenvolveu, no processo histórico, a necessidade de enculturar-se; que cada ser humano passe a fazer parte de uma comunidade de práticas não atende apenas a uma demanda social, mas também subjetiva. Avançar nessa direção é o papel que se atribui à psicologia semiótico-cultural.

De acordo com a perspectiva da psicologia semiótico-cultural, a cultura e o self são dimensões interdependentes, caracterizando-se como fenômenos de fronteira. Em outras palavras, o self se constitui por meio da internalização ativa dos sistemas de símbolos de sua cultura que, por sua vez, modifica-se no tempo pela ação intencional externalizada de cada pessoa, em suas interações sociais concretas. Na obra An Invitation to Cultural Psychology (Valsiner, 2014), o autor adensa o argumento acerca do caráter reconstrutivo e aberto da dinâmica psicológica de internalização-externalização semiótica, na qual se coconstituem o "infinito interior" (self) e o "infinito exterior" (cultura), como subsistemas da mesma semiosfera. Essa elaboração complementa e aprofunda a teoria dos campos afetivos (Valsiner, 2005, 2012), na qual o autor desenvolve a relação entre afetividade e cultura, ao estabelecer quatro níveis de desenvolvimento do signo no sistema de self $^{4}$. De acordo com o modelo por ele proposto, uns níveis representam processos semióticos em que os signos mostram-se mais permeáveis à mudança e outros, signos menos abertos à transformação - neste caso incluem-se aqueles que detêm uma carga afetiva maior, historicamente mais arraigada à sociocultura. Considera-se como sistema de signos hipergeneralizados, por exemplo, a matriz de valores e crenças que sustentam o funcionamento social de uma comunidade e que ela busca ativamente preservar por meio da transmissão horizontal e intergeracional.

4 Ver Mattos, 2016, neste volume.
Assim, de acordo com a teoria dos campos afetivos (Valsiner, 2005, 2012), o nível zero se refere a signos com alta permeabilidade à mudança e baixo grau de sedimentação, correspondentes à comunicação fática, ou às trocas que se reduzem a reações sensório-motoras. O nível 1 marca a emergência de signos relacionados a formas muito primárias de significação, por mero contraste (prazer/dor; claro/escuro, X/não X, por exemplo), o nível 2 e o nível 3 correspondem aos processos de produção de significados nos quais se identificam diferentes níveis de categorização e classificação da realidade em sistemas hierárquicos mais complexos e nos quais a intencionalidade do sujeito e seus afetos pessoais se colocam como parte intrínseca dos significados produzidos. Nesse sentido, é nesses dois níveis que ocorrem mudanças de significado mais profundas e que podem ter papel efetivamente reconstrutivo do self. O nível 4, diferente dos anteriores, de acordo com o modelo dos campos afetivos, corresponde aos significados inseridos em sistemas semióticos historicamente consolidados porque aglutinam significados afetivamente carregados e altamente relevantes para a organização sistêmica da cultura.

O modelo dos campos afetivos concebe a ação dos signos sobre o sistema de self desde uma perspectiva em que as orientações para significados vão do corporal (nível 0) ao social (nível 4), passando pelas que são propriamente psicológicas (níveis 2 e 3). Os signos hipergeneralizados orientam as ações concretas sem que, muitas vezes, suas marcas sejam reconhecidas, como tais, pelos os indivíduos, que podem não se dar conta de sua função social e de sua força propulsora da conduta individual.

Neste trabalho, pretendemos oferecer uma reelaboração da teoria dos campos afetivos, contrapondo à hipótese dos signos hipergeneralizados um novo construto, a saber, os signos hiperindividualizados. Enquanto o primeiro tipo reproduz-se porque veicula valores necessários à conservação da cultura, os signos hiperindividualizados respondem pela continuidade do self. Se o sentido de si mesmo se constitui como efeito da dinâmica ininterrupta de internalização, recriação e reificação de signos, que dão origem ao "infinito interior" (Valsiner, 2012), o selfé o produto dessa internalização criativa - e potencialmente única - dos sistemas simbólicos da cultura pela pessoa, mediado por seu próprio sistema de crenças e afetos. Compreendese que, no processo ontogenético, a internalização tende a criar sentidos subjetivos tão radicalmente singulares que tendem a se tornar incomunicáveis. Para ser parte da comunicação intersubjetiva, precisam ser traduzidos para alguma linguagem compartilhada com o interlocutor, e para serem compreendidos necessita-se de um olhar interpretativo, sensível à totalidade do outro. Nossa hipótese em elaboração é que os signos hiperindividualizados correspondem ao núcleo da estrutura do self, que viabilizam a construção do sentido de continuidade e estabilidade em meio à constante diferenciação operada pela irreversibilidade do tempo. 


\section{Estrutura, experiência e tempo no desenvolvimento do self dialógico}

A abordagem da psicologia dialógica tem se dedicado com afinco a teorizar sobre a configuração do self, sendo grande a oferta de modelos que representam tal configuração em dado momento da linha biográfica, segundo um corte sincrônico. Entretanto, a nosso ver, o campo ainda carece de bases para fazer avançar a níveis compreensivos satisfatórios a interpretação de processos de desenvolvimento da pessoa, quando se consideram os distintos cortes e níveis temporais.

Essa característica, que se pode identificar ao longo do desenvolvimento da pesquisa na área, torna-se crítica quando se buscam ferramentas teórico-metodológicas para a compreensão do desenvolvimento global da unidade psicológica da pessoa, em bases não normativas ou meramente descritivas, coerentes com os princípios relacionais do dialogismo. De modo particular, nota-se que algumas das tentativas já efetuadas de se buscar incluir o tempo intransitivo nos modelos interpretativos do self dialógico chegam a resultados limitados. Identifica-se a dificuldade de se integrar no mesmo plano de análise mais de um nível temporal (microgenético, mesogenético, ontogenético e histórico-social; cf. Vygotsky, 1989; Rossetti-Ferreira et al., 2004), o que resulta em um panorama incompleto e parcial da dinâmica desenvolvimental do self, tal como pudemos identificar na revisão de alguns estudos dedicados ao tema, que se mostram ora basicamente descritivos (Hermans \& Hermans-Konopka, 2010) ora limitando-se à ênfase nos aspectos microgenéticos (Salgado \& Cunha, 2012; Herrera, 2014) ou mesogenéticos (Toledo, 2014).

Outra dificuldade enfrentada no estudo do desenvolvimento do self dialógico é de ordem metodológica. $\mathrm{O}$ consenso entre os dialogistas diante do caráter historiado da conduta humana (Bruner, 1993; Sarbin, 1986) tem contribuído para certo reducionismo metodológico, ou seja, a tendência predominante a se reduzir os estudos do self a estudos com narrativas (terapêuticas, de entrevista). Esse tema abre espaço para a questão sobre a possibilidade de se reduzir a experiência do self ao que é narrativizado e tornado público na forma de relatos verbais (Lopes de Oliveira, 2013).

Um terceiro tópico que as teorias e perspectivas antes apresentadas ajudam a iluminar é o que decorre da tensão entre novidade e continuidade, mudança e permanência, base comum e idiossincrasia pessoal - e respectivos impactos numa possível estrutura mínima do self dialógico que se mantenha (ou se modifique em ritmo mais lento), para além da dinamicidade das relações e experiências cotidianas. A pergunta que se coloca envolve o papel relativo de estrutura e experiência situada na constituição e transformação do self dialógico. Essa pergunta perpassa a análise de estudo de caso que vamos apresentar, na sequência.

\section{O estudo empírico}

Um dos temas de investigação em que a tensão entre estrutura e experiência se desenha de modo particularmente instigante é o gênero (Lopes de Oliveira \& Madureira, 2014). De acordo com o paradigma feminista, o caráter gendrado da subjetividade constitui um aspecto intrínseco da pessoa e que perpassa as relações humanas. Ao mesmo tempo, na contemporaneidade, nota-se que as relações de gênero configuram-se como uma das importantes arenas ideológicas, nas quais a relação entre cultura pessoal e cultura coletiva se manifesta de modo mais ativo, revelando a diversidade de expressões que caracterizam a vida humana e a pluralidade de concepções - muitas vezes contraditórias e antagônicas - que a constituem. Manter a coerência com a perspectiva semiótica e dialógica incorporada a este trabalho exige abrir mão de abordagens que considerem o gênero como uma dimensão estruturante do self, segundo uma via unidirecional (cf. alguns dos modelos teóricos feministas) e compreender o gênero como um fenômeno cultural, em si mesmo plural, que se transforma historicamente de modo não linear, passível de desenvolvimento nos planos sociocultural e pessoal. Nesse sentido, a característica generificada do self dialógico constitui-se e modifica-se em relação de interdependência e perene contradição entre sistemas de valores e crenças socioculturais, de um lado, e pessoais, de outro.

Assim sendo, considerando a necessidade de estudos que se dediquem a compreender o desenvolvimento do self dialógico, propusemo-nos a reanalisar informações extraídas de um estudo de caso que se refere a um adolescente com performance de gênero não normativa. $\mathrm{O}$ eixo da nova análise está na dinâmica de desenvolvimento do self dialógico em distintos níveis temporais. Trata-se de um dos casos investigados por Toledo (2014) em pesquisa realizada sob a orientação da autora deste artigo. Tomando por base de análise uma composição entre o paradigma dialógico e os estudos de gênero, ele investigou os processos de desenvolvimento do sistema de self de adolescentes que apresentavam performances de gênero não normativas.

O conceito de performance de gênero provém de uma das linhas de desenvolvimento teórico do feminismo, a teoria queer, perspectiva que se autodenomina como uma teoria pós-identitária (Santos, 2006). De acordo com a teoria queer, o gênero é um sistema aberto, em constante reconfiguração, e que se expressa por meio de atuações situacionais, que se forjam em conformidade ao contexto, o outro e o significado da relação, entre outros fatores. Desse modo, as chamadas performances de gênero não normativas caracterizam-se como expressões subjetivadas dos papéis sociais de gênero, que são consideradas divergentes, quando comparadas aos padrões heteronormativos dominantes. A tensão que pode se estabelecer, na constituição da identidade de gênero de algumas pessoas, entre a pressão social para a adoção de padrões normativos heterossexuais e a própria autonomia subjetiva para proceder escolhas relativas à expressão e às interações de gênero conduz a zonas de ambivalência e ambiguidade, 0 que contribui para a emergência de novos significados sobre si e sobre o outro, a serem potencialmente integrados ao sistema de self. 
É possível supor que a relação entre valores socioculturais e processos de subjetivação, no plano da identidade de gênero, detém peculiaridades específicas, quando os investigados são adolescentes. Esse momento do desenvolvimento ontogenético caracteriza-se pela exacerbação de um conjunto de processos de mudança, em especial, nos campos da educação, do trabalho e da família (Mattos, 2013). Também são importantes os processos de desenvolvimento nucleados em torno do amadurecimento afetivo e sexual, âmbitos em que se sobressai o tema do gênero. Consideramos essa configuração de fatores um cenário produtivo para as investigações do desenvolvimento do self, com a vantagem de integrar outros elementos à análise, relacionados à expressão estética e afetivo-emocional, as quais encontram-se inscritas na corporeidade, permitindo ampliar as interpretações e levando à compreensão das novas posições do self, indo-se além do plano meramente enunciativo.

As novas posições que emergem ao longo da adolescência contribuem tanto para a desestabilização como para a integração dos planos temporais (passado, presente e futuro) e perspectivas do adolescente, levando necessariamente à reconfiguração da arquitetura do self e a novas autoimagens. Essa nova arquitetura não é, entretanto, definitiva. A natureza dialógica das posições emergentes faz que elas sejam sempre provisórias, uma obra em construção, orientada ao futuro e aberta a novas transições. O conceito de transição (Zittoun, 2014; Matos, 2013) refere-se aos momentos cruciais da vida, em que se é impulsionado a novos níveis qualitativamente diferenciados de funcionamento psíquico. $\mathrm{O}$ estudo das transições de desenvolvimento aponta que os momentos marcados por ambivalência são fundamentais para a emergência de novos sentidos que se convertem em recursos subjetivos para o desenvolvimento.

\section{Caracterização do caso Robson}

O caso a ser aqui apresentado mostra-se particularmente instigante para o estudo do desenvolvimento do self pois, ao tema do gênero, somam-se duas outras dimensões que também tendem a constituir, conforme o caso, fatores importantes para a configuração das posições dominantes do self, e que vamos explorar adiante: etnia e religião. A construção de informações de pesquisa foi longitudinal, considerando a fase de atendimento clínico e de realização de entrevistas de pesquisa. Robson (nome fictício) acabara de completar 18 anos quando, em maio de 2013, foram realizadas as entrevistas de pesquisa. Entretanto, os pesquisadores haviam feito o primeiro contato com ele em 2011, quando Robson iniciou tratamento psicológico no mesmo centro de saúde onde foi realizada a pesquisa. A família buscou atendimento com a queixa de abandono escolar e isolamento social. Entre 2011 e 2012, ele foi acompanhado por dois profissionais em separado, sendo um terapeuta familiar e um psicólogo clínico, autor da pesquisa. Entretanto, o quadro clínico não se alterou após quase um ano de atendimento, nem foram alcançados avanços em termos de hipóteses clínicas que permitissem identificar os fatores que levavam aos sintomas motivadores da queixa. Apresentamos abaixo, de modo esquemático, a configuração do self de Robson, que se construiu tomando por base os processos e mudanças ocorridos durante o período que vai do acompanhamento clínico de Robson às entrevistas de pesquisa. A análise das mudanças aponta para três complexos semióticos, percebidos como centrais na construção dos sistemas de significados pessoais do adolescente, quando se analisam os dois momentos da pesquisa.

Complexo semiótico 1 - Orientação sexual/gênero. Ao fim de 2012, o tema da orientação sexual emergiu em psicoterapia, quando o adolescente pôde revelar sua posição avessa aos papeis tradicionais de gênero e a adoção de uma conduta social feminina, a qual foi objeto de violências e perseguições de cunho homofóbico por toda sua trajetória escolar. A perseguição pelos colegas de escola se intensificou em 2011, e parecia não ser notada pelos professores, culminando no abandono escolar. As novas oportunidades de falar sobre gênero e sexualidade no contexto clínico e, a partir daí, também em família favoreceram o retorno de Robson à escola, em março de 2013, quando também o atendimento clínico foi interrompido, por decisão do adolescente. Nas entrevistas de pesquisa (realizadas entre maio e junho de 2013), ele relatou que continuava a ser vítima do comportamento homofóbico dos colegas de escola, mas que agora havia aprendido a lidar com esses comportamentos, adotando a estratégia que consistia em ignorá-los.

Complexo semiótico 2 - Raça/etnia. Um novo tema, não identificado na psicoterapia, surge no momento da pesquisa: o racismo. Nesse caso, o preconceito ao adolescente se revelava nas piadas e apelidos tendo por alvo as características do cabelo de Robson. Também no período da pesquisa, o adolescente se apresentou com os cabelos alisados e tingidos de cores como verde e prata.

Complexo semiótico 3 - Religião. A família de Robson é evangélica. $\mathrm{O}$ adolescente expressou manter um vínculo muito estreito com a igreja que frequenta, o que envolve uma relação afetuosa e de confiança com os pastores e demais fiéis. Dessa forma, o sistema de valores relacionados à sua orientação religiosa participaram da explicação atribuída por ele ao fenômeno central em análise neste trabalho, sua orientação sexual e de gênero. $\mathrm{O}$ adolescente considerava que sua orientação homoafetiva era a expressão de uma entidade espiritual que permaneceu por algum tempo incorporada a ele, a Pombagira; entretanto, a entidade havia sido retirada de seu corpo durante um culto evangélico em que foi também erradicado seu desejo por pessoas do mesmo sexo.

$\mathrm{O}$ foco das análises de pesquisa visou compreender a dinâmica das transformações do self de Robson no que se refere à emergência de novos posicionamentos sexuais e de gênero. De modo esquemático e necessariamente reducionista ao falhar em dar visibilidade a toda a complexidade dos eventos, essa dinâmica pode ser representada como oportunizando a transição entre três posições subjetivas que emergem em 
sequência, as quais são identificadas no intervalo temporal que vai do inicio do atendimento psicoterápico ao fim das entrevistas de pesquisa. Preliminarmente, estamos considerando as três posições como correspondendo a momentos diferenciados da trajetória ontogenética de Robson, a saber: (a) self "atuando" o gênero; (b) self como homossexual; (c) self como ex-homossexual. No entanto, a nosso ver, só é possível compreender essa transição biográfica (plano ontogenético) a partir de um olhar sensível e apurado dos processos microgenéticos. Considerar indicadores extraídos das narrativas de pesquisa e elementos da corporeidade, tendo em conta o modo como estes são atravessados por macronarrativas culturais no campo da religião e dos papéis de gênero.

Para fundamentar essa interpretação, relatamos aqui a discussão de uma parte dos resultados que, no caso, sustentam a transição entre (a/b) e (c), tendo por eixo a interseção deste complexo semiótico com os que se referem à religião e à raça.

\section{Discussão: o desenvolvimento da posição Eu (I/self) como homossexual $\times$ não homossexual - reverberações do contexto religioso}

Estudos de gênero tem evidenciado o papel das explicações religiosas no fenômeno do gênero (Lima, 2011; Oliveira, 2010). Considera-se que, em especial na cultura brasileira, a religiosidade constitua um marcador semiótico importante a ser considerado nas autodescrições sobre o desenvolvimento e a configuração pessoal do gênero. Dessa forma, na segunda entrevista de pesquisa, Robson apresenta um relato sobre eventos vivenciados no templo evangélico frequentado pela família, os quais estabelecem uma aproximação entre possessão religiosa e orientação sexual. Ele relata que, durante certo período de sua adolescência (que ele não especifica claramente), foi tomado pela possessão de espíritos malignos, a saber, a Pombagira e o Exu-caveira. Essas são entidades advindas da umbanda, religião de origem africana que se incorporou a outras tradições religiosas, como o espiritismo, segundo Oliveira, (2010). Exu-Caveira e Pombagira correspondem às versões masculina e feminina dos mesmos espíritos que se encontram em graus variados de evolução, que costumam se expressar em pessoas com pendores mediúnicos ou que sejam emocionalmente mais frágeis. Assim, trata-se de figuras religiosas distintas da orientação protestante seguida por Robson, o que não parece abalar sua crença na influência deles sobre sua subjetividade e sexualidade. Pode-se compreender, embora isso não tenha sido objeto de investigação, que matrizes simbólicas relacionadas à cultura africana possam fazer parte do ambiente social de Robson, tendo em conta suas origens étnicas.

Ele narra que, cerca de dois anos antes, quando se encontrava em uma fase pessoal muito ruim "em tempos péssimos" (comunicação pessoal; Toledo, 2014) - foi tomado pelas influências da "Pombagira da homossexualidade" (comunicação pessoal; Toledo, 2014). Afirmou que a manifestação desse espírito foi o evento responsável por ele passar a sentir desejo por homens e que o desejo homoafetivo foi suprimido dele durante um culto religioso, quando a entidade foi retirada de seu corpo por Deus e uma pastora, em uma sessão de exorcismo. A partir dessa experiência, ele deixou de se considerar homossexual e disse não sentir mais desejo sexual, nem por homens, nem por mulheres.

Alguns elementos dessa descrição são dignos de nota. O primeiro ponto refere-se ao enquadre religioso do desejo homoafetivo, no sentido amplo, e ao evento do exorcismo, em particular. O sistema de self de Robson convivia com uma ambivalência motivada pela tensão entre as posições "eu como afeminado/homossexual" $X$ "eu como protestante". Como exemplo, durante o atendimento clínico, ele havia relatado um episódio no qual havia sido perseguido e ofendido na rua por um grupo de pessoas, em função de seus maneirismos femininos. Ele ficou amedrontado e chegou a pensar que iriam atacá-lo quando então foi reconhecido por alguns membros de seu templo, que se afastaram dele por isso. A vivência religiosa, portanto, era protetiva quando Robson relata sentir-se bem nos cultos, mas um risco à sua integridade, pela rejeição homofóbica que os crentes de seu grupo religioso tinham ao grupo de gênero do qual ele fazia parte.

No que se refere à sessão de exorcismo, ele relatou na entrevista que, certo dia, ele assistia ao culto religioso quando a pastora anunciou no púlpito que havia na assembleia alguém com "a pombagira da homossexualidade". Robson relata que se apresentou espontaneamente à frente da assembleia e se ofereceu para a cura espiritual, aderindo dessa forma à oferta de significado sobre a homossexualidade feita pela instituição religiosa. Para esse grupo religioso, a homossexualidade é uma escolha ou opção consciente, a qual desvia o optante de Deus e o aproxima de entidades do mal; da mesma forma que alguém escolheu esse caminho, pode sair dele por vontade própria. No caso, a origem do desejo sexual de Robson é projetada pela pastora e por ele mesmo sobre uma alteridade transcendental, a "Pombagira", que é responsabilizada, em lugar de Robson, pela conduta sexual dele. A entrada desse novo signo em cena possibilita emergir uma nova tensão, no caso, entre as posições "Eu com a Pombagira/ homossexual" X "Eu sem a Pombagira/não homossexual". Ele relata que em meio às orações de exorcismo, ele "caiu duro", desmaiado e, quando voltou a si não apresentava mais qualquer desejo por pessoas de mesmo sexo e que, depois disso, até já havia experimentado alguma "curiosidade" em relação às meninas.

Nossa interpretação é que a tensão entre essas duas posições marca uma ruptura de desenvolvimento que afeta a continuidade do self de Robson, atuando como um marcador de desenvolvimento, ao possibilitar a emergência de algo que ele reconhece como uma nova posição de síntese. Essa posição é desenhada pela transição desde a condição de sujeito de desejo homoafetivo para o de 
objeto de controle religioso, portanto sem desejo sexual, à medida que este se extinguiu no exato momento em que a entidade Pombagira deixou seu corpo. Entretanto, compreendemos que rupturas e transições não constituem a supressão da tensão, mas sua transformação, ou seja, a substituição de uma forma de tensão por outra. No caso de Robson, o preciso momento do culto em que ele crê que a entidade maligna foi retirada de seu corpo permite emergir uma nova arena de negociação interna entre dois campos afetivos, que expressam a tensão entre prazer $(+)$ e sofrimento psíquico (-). De um lado, manter a conduta homossexual $(+)$ e continuar a sofrer preconceito (-), em diferentes esferas de atividade, entre as quais a escola e o templo; ou, neutralizar sua orientação sexual (-) e assim ser aceito nesses mesmos contextos (+), a partir de uma nova posição social de gênero (que não tem desejos por homens nem mulheres).

É interessante notar que é em meio a esse mesmo cenário de complexa diferenciação-integração subjetiva em busca de uma nova arquitetura de self que somos levados a supor que a tintura dos cabelos ganhe sentido como signo hiperindividualizado, ao servir de linguagem para ultrapassar os limites da negociação dialógica em âmbito verbal em face das vivências em que se é objeto de preconceitos. A alternância de cores do cabelo pode ser legitimamente compreendida como a exploração de um novo signo capaz de situar em novas bases as relações eu-outro, ao passo que tanto mascara os trejeitos femininos (signo de gênero) como o "cabelo ruim" (signo da matriz racial). No caso, o corpo passa a ser o suporte semiótico da configuração temporal do self, em que o pintar o cabelo em cores excêntricas surge como uma nova marca definidora da identidade pessoal, ao passo que esconde aquilo sobre o que é impossibilitado o diálogo.

\section{Considerações finais}

As transições de desenvolvimento vivenciadas por Robson no intervalo investigado tocaram dimensões do self fortemente marcadas por sistemas de crenças e valores enraizados, a exemplo de religião, gênero e raça. Tais sistemas permeiam e canalizam posicionamentos relacionados a diversos âmbitos da vida da pessoa, nos quais mecanismos de identificação e diferenciação entre posições do sujeito e sujeito-outro tanto concorrem para conformar o senso de si como para justificar preconceito e discriminação social.

Transições de desenvolvimento não se dão de modo linear, mas como parte de uma trama complexa, que envolve a mediação de diferentes alteridades (relacionadas ao contexto escolar, familiar, religioso e clínico, entre outros), sendo disparados por "gatilhos" relacionados a eventos e ruptura particulares. Buscamos avançar, considerando as análises proporcionadas pelo caso Robson, na compreensão da relação entre constituição de gênero e constituição do self, na adolescência. Identificamos, como ponto de partida, a impossibilidade de se identificar no gênero um fator constitutivo ou determinante do self, de modo independente de outras dimensões da vida, em torno das quais são nucleados os significados produzidos pela pessoa. Sistemas de experiências e inserções institucionais particulares tendem a fomentar - ou impossibilitar - algumas expressões subjetivas, tornando outras mais prováveis.

No que se refere a este caso específico, o tema da sexualidade é parte constitutiva de um complexo jogo figura-fundo que se entrelaça com os temas da raça/ etnia e da religião. Enquanto as interrelações gênero/ raça se expressam com mais vigor no contexto escolar, possivelmente, o complexo gênero/religião comparece de modo mais claro no templo e em outros contextos nos quais ele se percebe como alvo de discriminação e do preconceito dirigido aos homossexuais, em especial, pelos membros de sua comunidade religiosa. É em meio a estes intrincados complexos semióticos que o alisamento e a tintura do cabelo convertem-se em um signo de identidade, um mediador de posicionamentos estéticos de especial relevância, que parece funcionar simultaneamente como signo de atuação de identidade (self "na moda", contemporâneo/ousado/diferente) e como suporte de atuação social, catalisador da atenção do outro, ao propiciar um novo tema para a atribuição social de significados ao self, diverso do gênero, da raça e, possivelmente, da religião.

\title{
The development of the self and the process of hiper-individualization: inquiries to the Dialogical Psychology
}

\begin{abstract}
In Psychology the dialogical perspective is associated with various theories of self, in special, the Dialogical Self Theory (DST). Although important theoretical and methodological advances have been achieved by DST concerning our comprehension of the dynamic organization of the structure of the self in micro-genetic (temporal) processes, this perspective is in need of theories that explore in depth the development of the self including multiple temporal levels of organization and their mutual relationships. This paper aims to explore the triadic epistemological basis of the dialogical perspective in psychology, i.e., the cultural-semiotic basis, the phenomenology, and constructionism. Then, a case study concerning developmental transitions of an adolescent will be presented. We will analyze the semiotic complexes of gender, race and religion, as well as their role in the personal changes lived by him, in terms of the temporal organization of the self.
\end{abstract}

Keywords: Human development; dialogical perspective; developmental stabilization; theory of the affective fields; hiperindividualization. 


\section{Le développement du soi et les processus de l'hiperindividualisation: interrogations pour la Psychologie Dialogique}

Résumé: En psychologie, la perspective dialogique est associée à la théorie du soi (self) qui a été développée, en particulier, à travers les théories du soi dialogique (dialogic self theory; DST). Bien que des avancées théoriques et méthodologiques importantes aient été réalisées par les DST concernant notre compréhension de l'organisation dynamique des structures du soi chez les processus microgénétiques (temporels), ces théories requièrent des recherches qui explorent en profondeur le développement du soi, lesquels doivent porter sur les multiples niveaux temporels et leur rapport mutuel. Cet article propose d'explorer cette lacune à partir des approches dialogiques psychologiques, soit leurs bases sémiotique-culturelles, phénoménologiques et constructionnistes. Enfin, on analyse les complexes sémiotiques de genre, de race et de religion, ainsi que leur rôle sur le plan des changements de l'organisation temporelle du soi d'un adolescent.

Mots-clés: Le développement humain; l'approche dialogique; processus de stabilisation; la théorie de les champs affectives; I'hiperindividualisation.

\section{Desarrollo del self y proceso de hiperindividualización: cuestiones a la Psicología Dialógica}

Resumen: En psicología, a la mirada dialógica se la relacionan teorías del self, especialmente, la Teoría del Self Dialógico (TSD). Aunque haya avanzado significativamente en lo que atañe a la comprensión de la organización dinámica de la estructura del self en el tiempo microgenético, la perspectiva carece de estudios que profundicen la comprensión del desarrollo del self, tomando como base los distintos niveles temporales y sus relaciones. Este estudio se propone a explotar esta laguna a partir de la tríada epistemológica del abordaje dialógico, es decir, sus bases semiótico-culturales, fenomenológicas y construccionistas. Enseguida, presenta un estudio de caso en el que se analizarán transiciones de desarrollo de un adolescente, considerándose los complejos semióticos de género, raza y religión, y su papel en las transformaciones vividas en términos de organización temporal del self.

Palabras clave: desarrollo humano, enfoque dialógico, proceso de estabilización, teoría de los campos afectivos, hiperindividualización.

\section{Referências}

Bakhtin, M. (1989). Marxismo e filosofia da linguagem. São Paulo, SP: Hucitec.

Bakhtin, M. (1994). Preface. In M. Holquist \& V. Liapunov (Eds.), Towards a philosophy of the act (pp.X8-21). Austin, TX: University of Texas Press.

Bakhtin, M. (1997). Estética da Criacão Verbal. São Paulo, SP: Martins Fontes.

Bento, T., Cunha, C. C., \& Salgado, J. (2012). Dialogical theory of selfhood. In J. Valsiner (Org.), The Oxford handbook of culture and psychology (pp. 421-438). New York, NY: Oxford University Press.

Branco, A. U., \& Lopes de Oliveira, M. C. S. (2014). The dynamics of self-other relations in educational contexts: the dialogic construction of alterity. In V. Dazzini, M. Ristum, J. Marsico \& A. C. Bastos A.C. (Orgs.), Looking at inside and outside the educational contexts through cultural lens (pp. 79-93). Charlotte, NC: Information Age.

Bruner, J. (1993). Acts of meaning: four lectures on mind and culture. Cambridge, MA: Harvard University Press.

Buber, M. (2001). Eu e tu. (N. A. vun Zuben, trad.). São Paulo, SP: Centauro.

Chauí, M. (2002). Experiência do pensamento: ensaios sobre a obra de Merleau-Ponty. São Paulo, SP: Martins Fontes.
Cresswell, J. (2011). Being faithful: Bakhtin and a potential postmodern psychology of self. Culture \& Psychology, 17(4), 473-490.

Ericeira, R. C. S. (2007). História e vida mental: a psicologia dos povos Wundtiana. Trabalho completo apresentado no $14^{\circ}$ Encontro Nacional da ABRAPSO, Rio de Janeiro, Brasil.

Gaspar, Y.E., \& Mahfoud, M. (2006). Uma leitura histórica do conceito de experiência e uma proposta de compreensão do ser humano em seu caráter essencial: experiência elementar e suas implicações para a psicologia. In Anais do $5^{\circ}$ Encontro de Fenomenologia e Análises do Existir, São Paulo, Brasil. [Cd-rom]. UFMG.

Gergen, K. (1973). Social psychology as history. Journal of personality and social psychology, 26(2), 309-320.

Gomes, W. (2006). Notícia: IV International Conference on the Dialogical Self. Boletim Academia Paulista de Psicologia, 2(6), 99-102.

Gonçalves, R., Garcia, F., Dantas, J., \& Ewald, A. (2008). Merleau-Ponty, Sartre e Heidegger: três concepções de fenomenologia, três grandes filósofos. Estudos $e$ Pesquisas em Psicologia, 8(2), 396-346.

Hermans, H. (1992). The dialogical self: beyond individualism and rationalism. American Psychologist, 47(1), 23-33. 
Hermans, H. (2001). The dialogical self: toward a theory of personal and cultural positioning. Culture \& Psychology, 7(3), 243-281.

Hermans, H., \& Hermans-Konopka, A. (2010). Positioning and dialogue in life-long development. In dialogical self theory: positioning and counter positioning in a globalized world (pp. 200-253). Cambridge, UK: Cambridge University Press.

Holquist, M. (1993). The dialogic imagination: four essays by M. M. Bakhtin. Austin, TX: University of Texas Press.

Jahoda, G. (2012). Reflections on some definitions of culture. Culture \& Psychology, 18(3), 289-303.

James, W. (1890). The principles of Psychology. New York, NY: Henry Holt \& Co.

Kroeber, A. L., \& Kluckhohn, C. (1952). Culture, a critical review of concepts and definitions. Papers of the Peabody Museum of American Archaeology and Ethnology, 47(1), 1-223. Cambridge, MA: Harvard University Press.

Levinas, E. (2004). Entre nós: ensaios sobre a alteridade. Petrópolis, RJ: Vozes.

Lima, R. L. (2011). Diversidade, identidade de gênero e religião: algumas reflexões. Em Pauta, 9(28), 165-182.

Lopes de Oliveira, M. C. S. (2013). The Bakhtinian self and beyond: towards a dialogical phenomenology of the self. Culture \& Psychology, 19(2), 259-272.

Lopes de Oliveira, M. C. S., \& Madureira, A. F. A. (2014). Gênero e psicologia do desenvolvimento: quando a ciência é utilizada como força normatizadora das identidades de gênero. Labrys: estudos feministas, 2, 1-31.

Mattos, E. (2013). Self-development in the transition to adulthood: a longitudinal study with youth from Bahia. (Tese de doutorado não publicada). Universidade Federal da Bahia.

Meneses, R. D. B., \& Reis, A. M. M. G. (2009). Responsabilidade em Kant e Levinas: entre os conceitos e fundamentos. Ágora Filosófica, 9(2), 103-126

Moore, H. and Jasper, C. \& Gillespie, A. (2011). Moving between frames: the basis of the stable and dialogical self. Culture and psychology, 17 (4). pp. 510-519.

Oliveira, S. (2010). Psicanálise e umbanda: a demonização do Exu como interdição simbólica e intolerância religiosa. Revista Brasileira de História das Religiões, 3(8), 33-43.

Pino, A. (2005). As marcas do humano: às origens da constituição cultural da criança na perspectiva de Lev. S. Vygotsky. São Paulo, SP: Cortez.

Rasera, E. F., \& Japur, M. (2005). Os sentidos da construção social: o convite construcionista para a psicologia. Paidéia, 15(30), 21-29.

Herrera, F. J. R. (2014). Desenvolvimento de valores sociais na perspectiva da psicologia semiótico-cultural: um estudo com meninos brasileiros e colombianos em contexto lúdico sugestivo de violência. Tese de doutorado não publicada, Universidade de Brasília, Brasília, DF.
Salgado, J., \& Cunha, C. (2012). Positioning microanalysis: the development of a dialogically-based method for idiographic science. In S. Salvatore, A. Gennaro \& J. Valsiner (Orgs.), Making sense of infinite uniqueness: the emerging system of idiographic science (Vol. 4, pp. 95-123). Charlotte, NC: Information Age Publishing.

Salgado, J., \& Gonçalves, M. (2007). the dialogical self: social, personal and (un)conscious. In J. Valsiner \& A. Rosa (Eds.), The Cambridge handbook of sociocultural psychology (pp. 608-623). Cambridge, UK: Cambridge University Press.

Sampson, E. E. (2008). Celebrating the other: a dialogic account of human nature. Chagrin Falls, $\mathrm{OH}$ : Taos Institute. (Trabalho original publicado em 1993)

Santos, A. C. (2006). Estudos queer: identidades, contextos e ações coletivas. Revista Crítica de Ciências Sociais, $76,3-15$.

Sarbin, T. R. (1986). Narrative psychology: the storied nature of human conduct. Santa Barbara, CA: Praeger.

Simão, L. M. (2012). Otherness. In H. K. Anheier \& M. Juergensmeyer (Eds.), Encyclopedia of Global Studies (Vol. 4, pp. 1280-1281). Thousand Oaks, CA: Sage.

Taylor, C. (1997). As fontes do self. São Paulo, SP: Loyola.

Toledo, D. C. (2014). Performance de gênero não normativa na adolescência: contribuições da teoria do self dialógico. Dissertação de mestrado não publicada, Universidade de Brasília, Brasília, DF.

Valsiner, J. (2005). Affektive Entwicklung im kulturellen Kontext. In J. B. Asendorpf (Ed.), Soziale, emotionale und Persönlichkeitsentwicklung (pp. 677728). Göttingen, Alemanha: Hogrefe.

Valsiner, J. (2012). Fundamentos de psicologia cultural: mundos da mente, mundos da vida (A. C. Bastos, trad.). Porto Alegre, RS: Artmed.

Valsiner, J. (2014). Invitation to culture psychology. London, UK: Sage.

Vygotsky, L. (1989). A formação social da mente. São Paulo, SP: Martins Fontes.

Vygotsky, L. (2000). A construção do pensamento e da linguagem. São Paulo, SP: Martins Fontes.

Zittoun, T. (2014). Transitions as dynamic processes: a commentary. Learning, Culture and Social Interaction, $3(3), 232-236$.

Zuben, N. A. (2011). A fenomenologia como retorno à ontologia em Martin Heidegger. Trans/forma/ação, 34(2), 85-102. 